\title{
Evolución de un sistema de partidos: Cali 1990-2015*
}

\author{
Luis E. Gutiérrez ${ }^{1}$ \\ Universidad del Valle (Colombia)
}

Recibido: diciembre 19 de 2015. Revisado: marzo 15 de 2015. Aceptado: mayo 17 de 2016

Referencia formato APA: Gutiérrez, L. E. (2016). Evolución de un sistema de partidos: Cali 1990-2015. Rev. Guillermo de Ockham, 14(2), 155164. doi: http://dx.doi.org/10.21500/22563202.2408

\section{Resumen}

Este artículo explora la evolución del sistema de partidos en la ciudad de Cali entre los años 1990 y 2015. El foco está orientado al comportamiento electoral de los partidos y la composición de los concejos en el lapso estudiado. Con base en el empleo de indicadores como el número efectivo de partidos y el número de partidos se hace una descripción del sistema y un breve análisis de dos cambios institucionales: la Constitución de 1991 y la reforma política de 2003. El autor concluye que los dos partidos tradicionales pasaron de ser la fuerza dominante a participar en escenarios más competitivos perdiendo así la hegemonía de la representación política.

Palabras clave: Partidos políticos, sistemas de partidos locales, política subnacional, reforma política, fragmentación partidista

\section{Evolution of a party system: Cali 1990-2015}

\section{Abstract}

This paper explores the evolution of the party system in Cali between 1990 until 2015. The focus will be aimed toward the electoral behavior of the parties and the council's composing in the studied lapse. Based on the use of indicators, such as the number of effective parties and the number of parties, one description of the system and a brief analysis of two institutional changes are made: the constitution of 1991 and the political reform of 2003. The author concludes that the two traditional political parties moved from being the dominant strength to participating in more competitive context losing its hegemony.

Keywords: Political parties, parties system, subnational politic, electoral analyze, Colombia political parties

\section{Evolução de um sistema de partidos: Cali 1990-2015}

\section{Resumo}

Este artigo explora a evolução do sistema partidário na cidade de Cali, entre 1990 e 2015. O foco está orientado ao comportamento eleitoral dos partidos e da composição dos conselhos no período estudado. Com base na utilização de indicadores como o número efetivo de partidos e o número de partidos se faz uma descriçáo do sistema e uma breve análise de duas mudanças institucionais: a Constituição de 1991 e a reforma política de 2003 . O autor conclui

* El presente artículo se deriva del proyecto de investigación Outsiders, políticos a nivel subnacional: el caso de Jhon Maro Rodríguez en Cali, 2000.

1. Programa Estudios Políticos y Resolución de Conflictos de la Universidad del Valle.

Dirección postal: 760032318. E-mail: luis.g.rojas@correounivalle.edu.co 
que os dois partidos tradicionais que passaram de ser a orça dominante a participar em cenários mais competitivos perdendo assim a hegemonia da representação política.

Palavras-chave: Partidos Políticos, sistemas de partidos locais, política subnacional, reforma política, fragmentação de partidos

\section{Introducción}

Para estudiar el ascenso de los outsiders al poder ejecutivo (subnacional en este caso) es imperativo tener un panorama claro sobre el estado de los partidos políticos y el sistema que estos componen. ${ }^{2}$ El objetivo es ver por medio de diversos indicadores el comportamiento que ha tenido el sistema de partidos en esos veinticinco años y analizar los efectos que la Constitución de 1991 y la reforma política de 2003 tuvieron sobre él.

La conclusión apunta a que los partidos en la ciudad de Cali han atravesado procesos de crisis representados por pérdida de confianza y escasa filiación partidista de la ciudadanía, pero siguen teniendo vigencia electoral y han logrado adaptarse a los cambios institucionales y políticos. Los partidos tradicionales tuvieron un peso importante en la conformación de los concejos, pero después de 2003 han sido puestos en entornos más competitivos y han perdido el monopolio de la representación política (Ungar \& Arévalo, 2004).

Dicha crisis no es situación exclusiva de Colombia ni de los países latinoamericanos (Boudon, 1996; Vargas, 1994; Roll, 2002; Kenney, 2004, Chomsky, 2015). También Montero, Gunther, \& Linz (2007), recopilan reflexiones sobre los partidos políticos en Europa occidental y la crisis por la que atraviesan y otros aseguran que esta no es exclusiva de los partidos, sino de todo el sistema democrático (Medellín, 2005).

¿Dónde se puede datar el inicio de esta crisis de los partidos políticos en Colombia? Hay un amplio consenso en el sentido de que inició con el desmonte del Frente Nacional e incluso con el inicio de este pacto consociacional (Duque, 2011; Roll, 2002). Hay dos razones para justificarlo: la primera es que con la paridad en los cargos y las corporaciones públicas los partidos ya no tenían la necesidad de generar programas para ganar electores, pues no precisaban competir entre sí y las diferencias ideológicas se difuminaron. El segundo argumento es que el Frente Nacional, aunque ayudó a cerrar el ciclo de violencia que se venía presentando desde la mitad del siglo $\mathrm{XX}$, despolitizó la población y les cerró las puertas a otras formas de representación política que no fueran liberales o conservadores (Ungar \& Arévalo, 2004; Giraldo, 2007).

Esto generó, como lo expresan Gutiérrez (2007) y Pizarro (2002), una competencia interna y los dos partidos tradicionales vieron el inicio de un proceso de implosión que culminó en el año 2002 con más de mil listas inscritas para las elecciones al Congreso (tanto para el Senado como para la Cámara). La lucha ya no fue entre partidos ni plataformas programáticas o ideológicas, sino entre líderes y facciones en extremo personalistas.

Era tal el nivel de desorganización, indisciplina y personalización de la vida política que el sistema de partidos llegó a ser catalogado como el más personalista del mundo (Pizarro, 2008). Se hacía urgente una medida que retuviera la atomización y el fraccionamiento de los partidos políticos, situación que de no haberse detenido podría haber conducido a un punto sin retorno para estos. En el año $2003^{3}$ se aprobó una reforma que cambió profundamente el sistema electoral colombiano y el sistema de partidos.

Los análisis de sistemas de partidos a nivel subnacional son escasos y la literatura nacional no se ha encargado del asunto en profundidad. Sin embargo, hay trabajos como el de Arenas y Bedoya $(2009,2015)$ y Arenas, Bedoya \& Echeverry (2011) que analizan el caso de Medellín entre 1988 y 2007 y dibujan un panorama similar al de Cali, a saber, unos partidos fragmentados en su interior con gran variedad de facciones antes del año 2000 y una pérdida de terreno electoral de los dos partidos tradicionales después de 2003. Hoyos (2005) estudió con base en la volatilidad electoral y el número efectivo de partidos el comportamiento del sistema en 537 municipios. En Cali ha habido acercamientos con algunos trabajos como el de Vanegas (2008), pero el panorama a nivel subnacional y en la ciudad sigue siendo limitado y hay un amplio nicho de investigación.

\section{Método}

De acuerdo con el argumento planteado por Venesson (2013), este escrito se cobija bajo la categoría de estudio

2. En el transcurso de la investigación se determinó que una de las variables para explicar el fenómeno de los outsiders es la crisis de los partidos políticos y se sigue la línea que estos son la principal institución democrática y representativa (Montero, Gunther, \& Linz, 2007).

3. Para un análisis detallado, no solo de esta sino también de la reforma de 2009, véase Puyana (2012). 
de caso descriptivo (configurativo-ideográfico), el cual no tiene una intención teórica explicativa sino que pretende hacer una descripción explícita de un caso en particular.

Es sabido que este diseño metodológico puede tener limitaciones, como la validez y la confiabilidad de los resultados debido al $\mathrm{N}$ pequeño, el sesgo de selección del caso y la escasa capacidad para generalizar, entre otros (Solano, 2005). Sin embargo, ofrece un panorama específico de la ciudad en un periodo determinado y se acerca a interpretaciones teóricas sobre momentos particulares en ese lapso (Ragin, 2007).

Tiene un punto de vista basado en dos criterios fundamentales que guiarán el artículo: uno institucional, que hará énfasis en los cambios constitucionales efectuados en 1991 y 2003 principalmente, y un criterio cuantitativo, ya que se empleará información numérica como conformación de concejos, votación, porcentajes, proporciones e indicadores, entre otros, que provienen de la base de datos de la Registraduría Nacional del Estado Civil (Reginal) y de la base de datos del Centro de Estudios sobre Desarrollo Económico (CEDE), de la Universidad de los Andes.

Para efectos del análisis del periodo 1990-2000 y con base en el marco institucional que permitía la proliferación de múltiples listas por partidos y la doble militancia, las facciones y fracciones que coexistían dentro los partidos serán tomadas como una sola, ya sea Partido Liberal Colombiano (PLC) o Partido Conservador Colombiano (PCC). ${ }^{4}$

Se emplearán indicadores como el índice de concentración, ${ }^{5}$ el número efectivo de partidos (NEP) de Laakso y Tagapera ${ }^{6}$ y el número de partidos (NP) de Molinar $^{7}$ (Molinar, 1991; Ocaña y Oñate, 1991). Por último, se utilizarán fuentes hemerográficas, principalmente para el periodo comprendido entre 1990 y 2000, con el fin de observar la cantidad de facciones de los partidos políticos tradicionales.

\section{Resultado}

Una vez se ha expuesto brevemente la discusión académica nacional en torno a los partidos políticos y al sistema que conforman, desde una mirada principalmente (o tal vez exclusivamente) institucional, se ha de bajar un nivel y analizarlos en lo subnacional. Pero antes de continuar hay que hacer una advertencia y una reflexión: Mainwaring (2006) es claro al afirmar que gran parte de la literatura comparatista sobre partidos y sistema de partidos está dominada por análisis efectuados para Europa occidental y Estados Unidos. Al respecto, reflexiona sobre la teoría de Giovanni Sartori y afirma que las categorías producidas por el italiano no serían aplicables a algunos países de América Latina, entre ellos Colombia. Mainwaring asegura que esto así porque se pasa por alto una variable muy importante al intentar clasificar los sistemas de partidos en los países de la tercera ola de democratización (según el argumento de Samuel Huntington), entre los que se incluyen los países latinoamericanos: la institucionalización.

Como no es el objetivo del artículo hacer un debate teórico profundo sobre este tema, ni sobre lo que puede ser o no un partido, es importante señalar que aquí no se abordará el sistema de partidos con base en la institucionalización, lo cual no implica que no se mencione de una u otra manera este aspecto. Pero el criterio numérico va a ser la columna vertebral del texto. Por tal razón, la clasificación y el análisis de la evolución del sistema en la ciudad se hará tomando en cuenta varios factores relacionados con lo electoral, la dispersión de los partidos y la relación concejo-alcaldía, entre otros que quedarán claros en los siguientes párrafos.

La discusión local tendrá una visión institucional, pero se tomará en consideración los factores sociales y económicos claves para entender la dinámica en la ciudad, principalmente para hacer una comparación -en términos de comportamiento electoral- del ejecutivo frente al legislativo y viceversa. Por tal razón, se mencionarán indicadores socioeconómicos y se hará una descripción de las situaciones políticas, como los escándalos de corrupción de las administraciones, la difícil situación económica del año 1999 que afectó a toda Colombia, el recrudecimiento del conflicto armado interno y el accionar de las FARC y el ELN en la ciudad, entre otros.

Se ha decidido periodizar el lapso estudiado, así: 1. 1990 a 2000: aquí los partidos tradicionales fueron siempre la fuerza dominante en el Concejo municipal, concentraron las mayorías legislativas y electorales y cuatro de

4. Entre 1990 y 1992 el PCC se llamó Partido Social Conservador

5. El índice de concentración es la sumatoria de las dos proporciones más altas, ya sea en votos o en escaños.

6. El índice de número efectivo de partidos se calcula dividiendo 1 por las sumatorias de las proporciones al cuadrado. La fórmula se representa $\mathrm{N}=$, donde pi es la proporción de votos o escaños que consigue cada partido.

7. El índice número de partidos se calcula con la sumatoria de las proporciones al cuadrado excepto del partido ganador, ya que este se suma como 1. $\mathrm{Al}$ ser una derivación del NEP, se emplea el resultado que se obtenga de este, por eso la fórmula es así: $\mathrm{NP}=1+\mathrm{N} 2$, donde pi es la proporción de votos o escańos que consigue cada partido. 
las cinco alcaldías en disputa fueron ganadas por liberales o conservadores. Es un periodo de rápido crecimiento económico hasta 1996 y luego de una profunda crisis económica y fiscal en 1999 y 2000. La ciudad estuvo a punto de quebrar y someterse a la ley $550^{8}$ (Alcaldía de Santiago de Cali, 2008). El año 2000 marca un antes y un después, ya que a partir de este momento ninguno de los partidos tradicionales ni tampoco los nuevos han logrado ganar la alcaldía, la cual siempre ha quedado en manos de un movimiento significativo de ciudadanos; ${ }^{9} 2$. 2003 a 2011: es a partir de este momento que el sistema experimenta un cambio, ya que entra en vigor la reforma política, el sistema de partidos se empieza a fragmentar y tanto el PLC como el PCC a pierden las mayorías en el Concejo, al punto de que en el ańo 2011 los rojos consiguieron solo dos escaños de un total de veintiuno; 3. 2011 hasta hoy: el sistema de partidos se afirma como un multipartidismo moderado, aparecen en el escenario nuevas fuerzas políticas y llegan a la alcaldía (uno en 2011, otro en 2015) dos políticos vinculados a la élite política de la ciudad, lo que rompe con lo que algunos comentaristas de los medios han llamado de manera apresurada, una serie de "alcaldes populistas" (Jhon Maro Rodríguez en el 2000, Apolinar Salcedo en 2003 y Jorge Iván Ospina en 2007).

\section{0-2000: el dominio de los tradicionales}

En este periodo predominan claramente los dos partidos tradicionales (Figura 1), los cuales controlaron más del $50 \%$ de los escaños en la corporación local y de las cinco alcaldías, tres fueron conservadoras y una liberal. De otro lado, la izquierda, representada por la Alianza Nacional Popular (Anapo) y la Alianza Democrática M-19 (AD-M19) obtuvieron una escasa representación. El movimiento que lideró uno de los periodistas más conocidos de la ciudad, Humberto Pava Camelo, perdió presencia en el Concejo, pues en 1988 lograron cinco curules y después de 1990 el Movimiento de Acción Social (MAS) se redujo en representación. También hicieron una ligera presencia el Movimiento Cívico Cristiano (MC-4), el Movimiento Cívico Independiente (MCI) y el Movimiento Popular Unido (MPU), este último vinculado con políticos que han afrontado problemas con la justicia, como el exsenador Carlos Herney Abadía.
Figura 1

Conformación del Concejo municipal

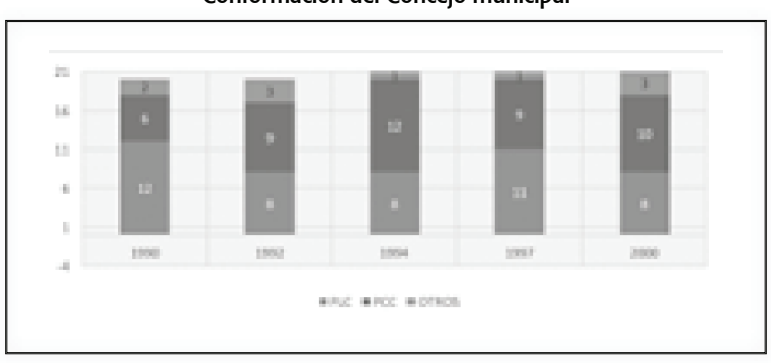

Fuente: elaboración propia con base en datos del CEDE y Reginal.

Entre 1990 y 2000 convivieron en los dos partidos tradicionales varias facciones que consiguieron representación en el Concejo. Aunque fueron más las liberales, los conservadores también estaban divididos en facciones personalistas que se construyeron alrededor de la figura de políticos con proyección nacional. Por los liberales aparecían nombres como el del exalcalde y exministro Carlos Holmes Trujillo y por los conservadores, el exministro Carlos Holguín Sardi con su movimiento. El Cuadro 1 muestra todas las facciones y fracciones que estuvieron representadas en el Concejo municipal.

\section{Cuadro 1}

Facciones y fracciones de los partidos Liberal y Conservador, 1990-2000

\begin{tabular}{|c|c|}
\hline Partido & Facción/Fracción \\
\hline PLC & $\begin{array}{l}\text { Renovación Liberal, londoñismo; Movimiento de las } \\
\text { Mayorías Liberales, Holmismo; Fuerza Liberal Social- } \\
\text { demócrata; balcarcismo; Brigada Social Liberal; Frente } \\
\text { Liberal del Valle; Movimiento Liberal Unido; Alternativa } \\
\text { Liberal Popular; becerrismo; Nuevo ciudadano; Nuevo } \\
\text { liberalismo. }\end{array}$ \\
\hline PCC & $\begin{array}{l}\text { lloredismo; holguinismo; humbertismo; Conservatismo } \\
\text { Independiente; Movimiento de Salvación Nacional. }\end{array}$ \\
\hline
\end{tabular}

Cabe anotar que las élites de ambos partidos trabajaron de manera conjunta a tal nivel, que para las elecciones de 1994 decidieron "repartirse" la alcaldía y la gobernación del Valle del Cauca en una alianza denominada "la clave", que Pinto Ocampo (2011) lo asemeja al pacto del Frente Nacional. Mauricio Guzmán, el candidato a la alcaldía del PLC y perteneciente al Nuevo Liberalismo, apoyó la candidatura de Germán Villegas Villegas a la gobernación de Valle del Cauca y este, junto con otros miembros del PCC, apoyaron a Guzmán en su aspiración roja. Para los comicios de 1997, el candidato ganador, Ricardo Cobo Lloreda, intentó repetir la fórmula, pero no se pudo concretar ningún acuerdo.

8. Véase: La reforma al congelador (2000, 30 de septiembre). El País, p. B1; Cali debe darse la pela (2000, 01 de septiembre). El País, p. B4. Reforma no da espera (2000, 04 de octubre). El País, p. C1.

9. La única excepción fue Apolinar Salcedo, quien ganó la alcaldía con el movimiento Sí Colombia, liderado por la excandidata presidencial Noemí Sanín. Sin embargo, el movimiento manejaba un discurso antipartidista y se definía como suprapartidista.

Véase: http://www.colombia.com/especiales/elecciones_2002/perfiles/noemi/movimiento.asp 
Para el 2000 se produce la elección del primer alcalde desligado de las clases políticas tradicionales de la ciudad. Jhon Maro Rodríguez, un locutor de radio de la cadena $\mathrm{RCN}$, derrota a los liberales y conservadores en los comicios y se convierte en el primer outsider político en llegar al cargo en la ciudad, pero antes que Jhon Maro lograra el triunfo en las elecciones locales, el alcalde liberal Mauricio Guzmán debió renunciar en agosto de 1997 por presuntos nexos con el narcotráfico, ${ }^{10}$ mientras que el conservador Ricardo Cobo Lloreda terminó, en el año 2000, una gestión que dejaba una crisis económica y fiscal por los altos costos administrativos.

Estas dos circunstancias sirvieron para erosionar aún más la imagen de los partidos y las clases políticas. Una encuesta del año 2000 publicada en el diario El Tiempo, dejaba entrever que de los 496 entrevistados, el $60 \%$ no se identificaba con partido alguno; sin embargo, una situación que Llano (2001) expone claramente, se evidenció: a pesar de ganar un alcalde independiente, el PLC y el PCC siguieron siendo mayoría en el Concejo municipal (ver Figura 1). ${ }^{11}$

\section{3-2011: el cambio en el sistema}

Desde el año 2003 en adelante, el sistema de partidos experimenta un cambio. Como se aprecia en la Figura 2, los dos indicadores muestran un incremento; tanto el número efectivo de partidos (NEP), de Laakso y Tagapera y el número de partidos (NP), de Molinar (1991) muestran una tendencia al alza.

Si se emplea como guía el NP, se toma como complemento la Figura 2, se teoriza bajo la categorización de Sartori (2005) y se emplea el enfoque propuesto por Ware (2004), esto es, tomar los partidos por su tamaño relativo, cabría afirmar que entre en 1990 y 2000 hubo un bipartidismo en el que liberales y conservadores fragmentados en su interior- concentraron las mayorías legislativas, mientras las demás fuerzas políticas que consiguieron representación siempre lo hicieron en condición de minorías. Después de 2003, el sistema transitó de ese bipartidismo a un multipartidismo que se ha consolidado hasta hoy con la presencia de otras fuerzas políticas que se han mantenido desde el año 2007.
Figura 2
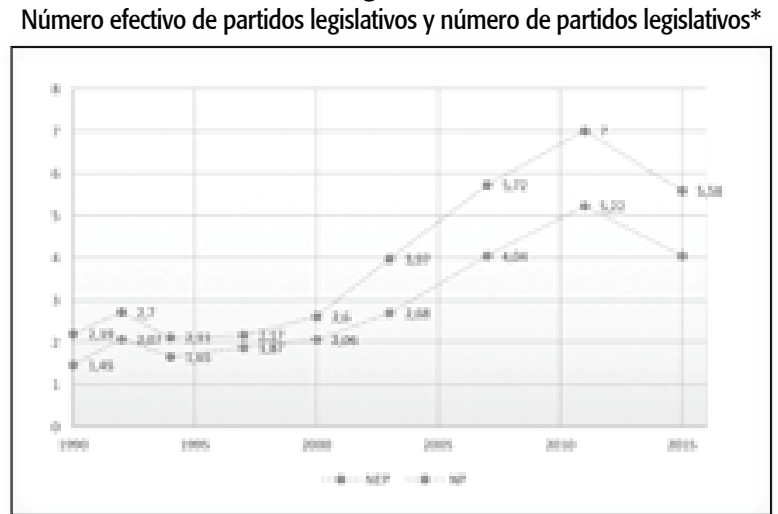

Fuente: elaboración propia con base en datos del CEDE y Reginal.

* En el 2015 hubo dos partidos que obtuvieron la misma proporción de escańos. El índice se calculó contando dos partidos $(2+)$ y no uno $(1+)$.

También cabe afirmar que el poder político se dispersó a partir del año 2007, cuando se efectúa la elección subsiguiente a la entrada en vigencia de la reforma política de 2003. A pesar de que el sistema tuvo su máxima fragmentación en el 2011 -año en que hubo diez partidos representados- en 2015 la tendencia se redujo, y en la misma vía la cantidad de partidos representados y el índice de concentración (Figura 3) se incrementaron, lo que lleva a la conclusión de que los dos partidos tradicionales se encuentran actualmente en una condición de minorías en competencia. De acuerdo con Duque, (2014), mientras en el 2011 los dos partidos mayoritarios fueron el La U (Partido Social de Unidad Nacional) y el PCC, en el 2015 lo fueron el PLC y nuevamente La U.

Si nos remitimos nuevamente a la Figura 2, se aprecian los dos momentos institucionales mencionados previamente: la Constitución de 1991 (C91) y la reforma política de 2003 (R03). Entre las elecciones de 1992 y 2000, el sistema de partidos no varió significativamente, ${ }^{12}$ como se observa al comparar el NEP y el NP. Es a partir de 2003 cuando ambos aumentan casi un $100 \%$ hasta el 2011, y en 2015 tanto el índice de concentración legislativa (CONC_L) como el NP varían de manera inversamente proporcional (Figura 3).

Los índices de concentración tanto electoral (CON_E) como legislativo (CONC_L), refuerzan el argumento de la pérdida de representación de los dos partidos políticos.

10. Véase: Revista Semana. "La caída de Guzmán”.

Recuperado de: http://www.semana.com/nacion/articulo/la-caida-de-guzman/33276-3

11. Este punto no se tratará en profundidad, ya que no es el principal interés de este artículo.

12. Se considera que un análisis más profundo del sistema de partidos debería analizar más elecciones previas a C91 y comprobar, empíricamente, si hubo un cambio o no; también se puede tomar la opción de contar las facciones de manera individual. 
Figura 3

Índice de concentración electoral y concentración legislativa

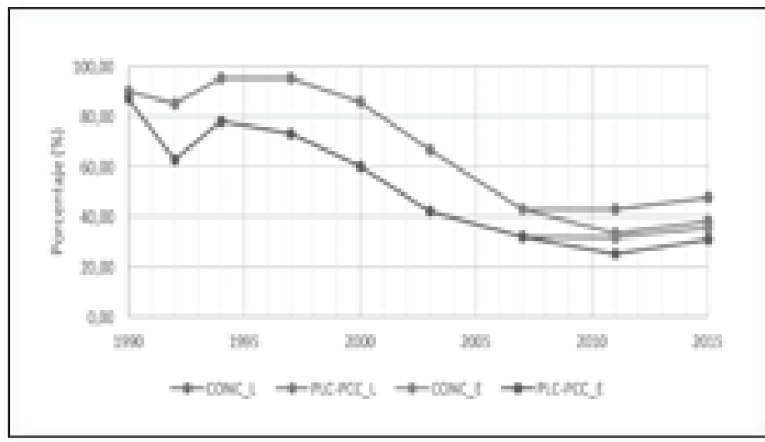

Fuente: elaboración propia con base en datos del CEDE y Reginal

Entre 1990 y el 2000, los dos partidos tradicionales concentraron más del $60 \%$ de la votación y del $80 \%$ de los escaños. Hasta el 2007 los dos índices coinciden con los porcentajes obtenidos por el PLC Y el PCC (PLC-PCC Ly PLC-PCC E), pero en el 2011 y en el 2015 perdieron las mayorías. Sin embargo, si se observa detenidamente se advierte que entre 1994 y 2000 los tradicionales perdieron tanto en el terreno legislativo como en el electoral, lo que muestra que la tendencia a la baja se venía presentando desde antes de la reforma política.

Obsérvese la composición del Concejo en el año 2003 (Figura 4). Se aprecia la presencia de nuevas fuerzas políticas; sin embargo, es una situación similar a la presentada en 1992: hay dos partidos que juntos controlan las mayorías legislativas $(67 \%)$ y varios partidos pequeños (un total de cinco partidos, solo uno con más de un escaño para 2003 y tres partidos con un escaño en 1992). Por esta razón, no se puede usar exclusivamente indicadores como el NEP o el NP, ya que el primero sobredimensiona a los partidos grandes y el segundo a los pequeños.

\section{Figura 4}

Conformación del Concejo 2003

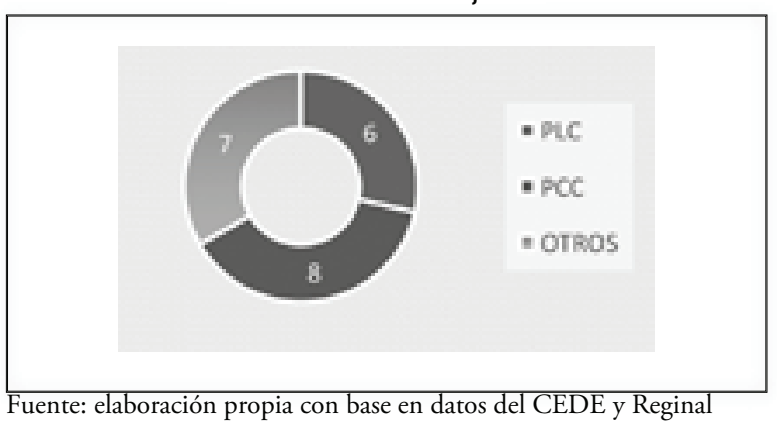

A pesar de que fue en estas elecciones (2003) cuando la reforma entró en vigor, no fue sino hasta los siguientes comicios que se sintieron sus efectos, ya sea por la implementación del umbral o por la lista única. Lo cierto es que hubo una reducción en el número de partidos reales que se presentaron a competencia.

Entre 1997 y 2003 hubo una explosión de partidos y movimientos que compitieron por las veintiuna curules del Concejo de la ciudad. En 1997, tan solo tres consiguieron representación, entre esos el PLC y el PCC. En 2011 hubo doce partidos en competencia y diez representados y en el 2015 doce y ocho, respectivamente (Figura 5). Esto evidencia que el marco legal implementado a partir de la reforma de 2003 ha permitido cambios importantes en el sistema, como la reducción del número de partidos.

En la Tabla 1 se hace una sencilla operación. en la primera columna se divide el total de partidos en competencia $(\mathrm{PeC})$ por los partidos representados $(\mathrm{Pr})$, y se obtiene una proporción $(\mathrm{Pi})$. Cuanto más se acerque el número a uno, significa que el sistema es más proporcional y cuanto más se aleje lo es menos. Por ejemplo, mientras que en 1997 la relación fue de 0,103, en el 2011 fue de 0,833 y en el 2015 de 0,666 . La segunda columna indica una relación igual de sencilla que, además, responde a la pregunta de cuántos partidos compiten por un escaño. Mientras que en 1997 el resultado fue de 1,38 en 2011 fue de 0,57, al igual que en el 2015. El sistema llegó a una saturación tal que por cada escaño había más de un partido compitiendo por él y si la operación se hubiera hecho por la cantidad total de listas inscritas el número hubiese aumentado dramáticamente.

Figura 5

Partidos en competencia electoral frente a partidos representados

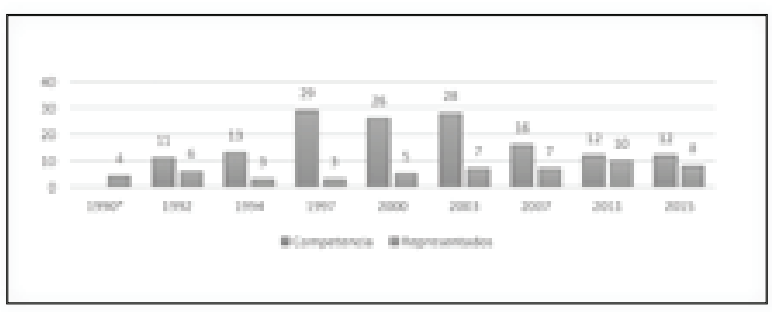

Fuente: elaboración propia con base en datos del CEDE y Reginal.

Tabla 1

Proporciones

\begin{tabular}{ccc}
\hline Año & $\mathbf{P i}=\mathbf{P e C} / \mathbf{P r}$ & $\mathbf{P i}=\mathbf{P e C} / \tilde{\mathbf{n}}$ \\
\hline $1990^{*}$ & --- & -- \\
\hline 1992 & 0,545 & 0,52 \\
\hline 1994 & 0,230 & 0,61 \\
\hline 1997 & 0,103 & 1,38 \\
\hline 2000 & 0,192 & 1,33 \\
\hline 2003 & 0,250 & 1,33 \\
\hline 2007 & 0,437 & 0,76 \\
\hline 2011 & 0,833 & 0,57 \\
\hline 2015 & 0,666 & 0,57 \\
\hline
\end{tabular}

Fuente: elaboración propia con base en datos del CEDE y Reginal. *No hay información suficiente para el análisis. 


\section{1-2015: el multipartidismo}

El inicio del tercer periodo propuesto está marcado por la llegada a la alcaldía de un político vinculado a la clase política caleña y vallecaucana, que sin embargo se presenta a elecciones con una etiqueta no partidista. Sin embargo -y esto es más importante- es cuando el sistema de partidos se afirma como un multipartidismo que aparecen en el escenario partidista nuevos actores que se apropian de los espacios copados por los dos tradicionales. Así, el PLC obtiene solo dos curules y La U se convierte en mayoría legislativa, hecho que repetirá en el 2015.

No pretendo extenderme en una explicación de este último factor, pero hay tres elementos importantes para resaltar: la recuperación del PLC como fuerza importante, la pérdida de curules del PCC que se ubicó por debajo de Cambio Radical (PCR) y la aparición de una nueva fuerza política, a saber, el Partido Centro Democrático (PCD) que consiguió una curul y empleó la lista cerrada. De otro lado, se tiene la presencia, en condición de minoría, del Polo Democrático Alternativo (PDA), el Partido Alianza Verde (Partido Verde) y el Movimiento Independiente de Renovación Absoluta (MIRA) (Figura 6).

A pesar de las medidas adoptadas, el personalismo persiste en la política local. En el PLC las facciones siguen presentes; Clementina Vélez, la concejal más antigua de la corporación tiene su movimiento propio; Carlos Pinilla, otrora representante del londoñismo, también lidera uno y el exconcejal Orlando Chicango le "heredó" la curul a su hijo; La U no se queda atrás, pues dos concejalas son del Movimiento Nueva Generación que lidera la actual gobernadora Dilián Francisca Toro y el PCC, por su parte, tiene como facción más fuerte al Movimiento Fuerza Social, del exgobernador Ubéimar Delgado con un concejal . No se puede desconocer que en los partidos hay tendencias, corrientes y opiniones diferentes; sin embargo, estas facciones se han construido con base en la figura del líder y no de una plataforma ideológica o programática clara.

Figura 6

Conformación del Concejo 2015

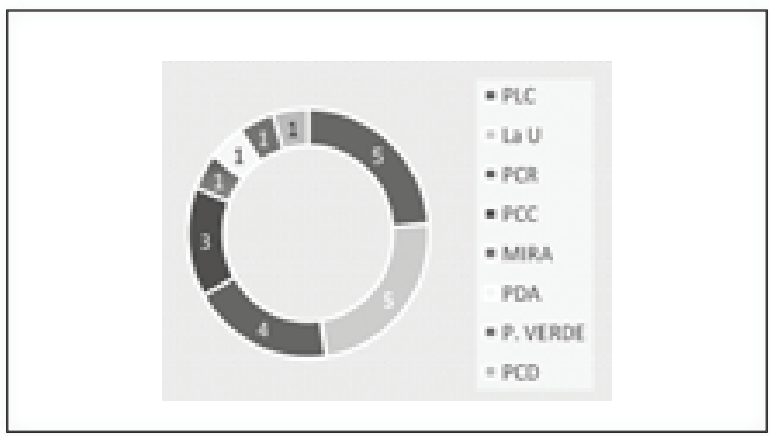

Fuente: elaboración propia con base en datos del CEDE y Reginal.
Por último, en cuanto al comportamiento electoral de los partidos (Figura 7), se confirma la tendencia que viene presentando el sistema: la pérdida de terreno de los dos partidos tradicionales que desde 1997 disminuyen su participación proporcional en la votación total.

A pesar de la pérdida de electores entre 2000 y 2003, ambos (PLC y PCC) conservaban la mayoría. Para una respuesta satisfactoria no hay que perder de vista el marco institucional: método del cociente y residuo; múltiples listas, aprobación de la doble militancia, etc. Además, en el 2000 el PLC presentó treinta y cinco listas y el PCC quince, amén de una proliferación de movimientos y partidos flash, como los denomina Pasquino (2011): "En particular, no serían partidos todos aquellos grupos que viven el espacio de una jornada (electoral) y son definidos como partidos flash, seguramente más flash que partidos" (p. 167). Estos causaron una amplia dispersión de la votación de los rojos y los azules, pues muchos de esos movimientos que iban y venían eran escisiones de los dos tradicionales.

Otro asunto para resaltar es la pérdida de protagonismo del PLC frente al conservatismo. Entre 2003 y 2011 los azules superaron a los rojos en las urnas, hecho que se reflejó en la conformación del Concejo del 2007 cuando los liberales alcanzaron solo tres curules y el PCC seis, situación que se revirtió en las elecciones del 2015.

Figura 7

Porcentaje de votación 1990-2015

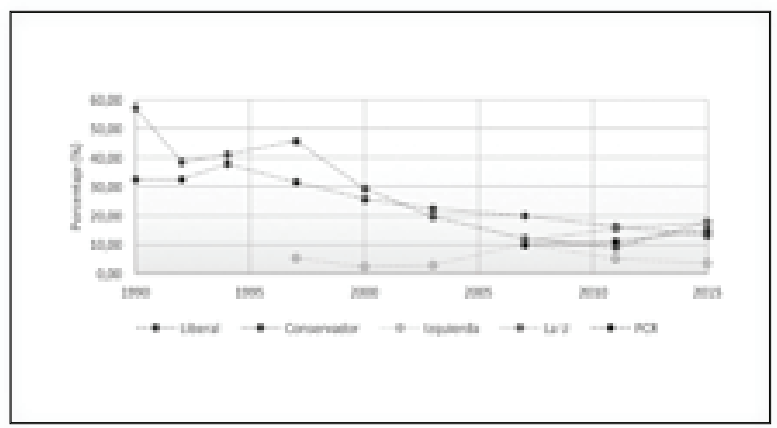

Fuente: elaboración propia con base en datos del CEDE y Reginal.

Otro punto importante es la escasa y casi siempre marginal presencia de la izquierda democrática. En 1997, cinco movimientos obtuvieron poco más del $5 \%$ de la votación; en el 2003 entra en escena el Polo Democrático Independiente -precursor del actual PDA- y obtiene el $2 \%$ de la votación total, junto con el MOIR. Es en el 2007 cuando la izquierda alcanza la máxima participación electoral al conseguir el $10 \%$ de la votación y dos curules, primera y única vez en todo el periodo de estudio que la izquierda es fuerte electoralmente hablando. 


\section{Discusión}

Como se mencionó al principio del artículo, la discusión subnacional debe ser transversal a la discusión nacional sobre el sistema de partidos de Colombia, lo que no implica desconocer que las unidades locales o regionales tienen comportamientos diferentes. Los partidos han atravesado periodos de crisis, pero han sabido adaptarse a los nuevos escenarios institucionales y superado los golpes de opinión ocasionados por escándalos de corrupción. Asimismo, los dos partidos tradicionales han logrado sobrevivir hasta la fecha a pesar de una notoria pérdida de poder.

La Constitución de 1991 introdujo cambios importantes tanto para el sistema político en general como para los partidos políticos, entre los que se tiene el haber abierto el camino para que movimientos diferentes a los partidos tradicionales accedieran al poder y salieran a la luz pública con solo cincuenta mil firmas. También se tiene la implementación de una circunscripción nacional para el Senado, lo que otorgaría -y así se previó- mayor representatividad. Esto condujo al aumento de la oferta política pero no al resultado deseado, pues a pesar de que se crearon nuevos movimientos y algunos lograron ingresar a la escena política, los partidos tradicionales siguieron dominando el escenario (Hoyos, 2005; Arenas y Bedoya, 2015).

Es luego de este cambio institucional cuando la fragmentación interna -que ya se evidenciaba- experimenta un salto cualitativo, la vida política interna de los partidos se atomiza y la competencia se torna más personalista. De acuerdo con Pizarro (2002), en este periodo se hace patente el fenómeno de las microempresas electorales "expresión en el plano electoral de las facciones personalistas, que en su sumatoria de representaciones fragmentadas, conforman un conjunto heterogéneo que todavía se llama partido" (p. 364). ${ }^{13}$

¿Por qué ocurrió esto? Igual que sucedió en Medellín (Arenas y Bedoya, 2009, 2015), en Cali el PLC y el PCC se fragmentaron a fin de no perder las mayorías legislativas. De este modo, se vieron se vieron enfrentados a la incertidumbre de que a mayor curules más fragmentación y por ende, menos cohesión. Según los datos del CEDE, el PLC presentó treinta y dos listas en 1994, sesenta y una en 1997 y treinta y cinco en el 2000. El PCC, por su parte, obtuvo dieciocho, veinte y quince en los mismos años.
Los resultados muestran un aumento de la oferta política en el primer periodo, pero la representación se concentró. La apertura del sistema de partidos se dio pasado el el 2003 justo cuando entra en vigencia una reforma que emplea una fórmula electoral menos proporcional y se implementa la lista única con voto preferente. La competencia cambió de contexto, subió un escalón, dejó de ser entre listas o facciones y se volvió partidista (Gutiérrez, 2007).

¿Cómo afectó la reforma el sistema de partidos en Cali? Para responder esta pregunta debe observarse el Cuadro 2 en el que se se desglosan los principales mecanismos introducidos que produjeron un cambio en la competencia electoral.

\section{Cuadro 2}

Mecanismos de la reforma política de 2003

\begin{tabular}{|c|c|}
\hline Mecanismo & Observaciones \\
\hline Fórmula electoral & $\begin{array}{l}\text { Se cambió la manera como se convierten } \\
\text { los votos en escaños. Antes de la reforma } \\
\text { se empleaba la fórmula Hare (cociente y } \\
\text { residuo) y posterior a esta se empleó D'hont } \\
\text { (cifra repartidora). }\end{array}$ \\
\hline Umbral electoral & $\begin{array}{l}\text { Aquellos partidos que no obtuvieran más de } \\
2 \% \text { de la votación en el Senado perderían } \\
\text { su personería jurídica. La reforma política } \\
\text { del } 2009 \text { lo aumentó al } 3 \% \text {. Para las demás } \\
\text { corporaciones el umbral quedó ubicado en el } \\
50 \% \text { del cociente. }\end{array}$ \\
\hline $\begin{array}{l}\text { Lista única. Voto } \\
\text { preferente }\end{array}$ & $\begin{array}{l}\text { Los partidos debían presentar una única lista } \\
\text { para las elecciones a corporaciones públicas } \\
\text { que no podía exceder el número de escańos } \\
\text { por proveer. Para el caso de Cali, se eligen } \\
\text { veintiún concejales; podía ser abierta o } \\
\text { cerrada. }\end{array}$ \\
\hline $\begin{array}{l}\text { Estructura interna de } \\
\text { los partidos }\end{array}$ & $\begin{array}{l}\text { A diferencia de la Constitución de } 1991 \text {, la } \\
\text { reforma instó a los partidos a organizarse } \\
\text { internamente de manea democrática. La } \\
\text { reforma política del } 2009 \text { los obligó a organi- } \\
\text { zar convenciones mínimo cada dos años. }\end{array}$ \\
\hline Bancadas & $\begin{array}{l}\text { El acto legislativo dejó un precedente para } \\
\text { que los partidos actuaran en bancadas. La } \\
\text { Ley } 974 \text { de } 2005 \text { las reguló. }\end{array}$ \\
\hline
\end{tabular}

Estos cambios incidieron no solo en los sistemas locales, sino también en el nacional. Con la lista única y la fórmula electoral D’hont, se buscaba premiar a los partidos que trabajaran en conjunto. Ya no había incentivos para dispersarse porque esta fórmula suma los votos de todos los candidatos y luego reparte los escaños con base en el candidato que obtuviere más votación. Esto puede producir un efecto de arrastre cuando determinado can-

13. Al respecto, Gutiérrez (2007) expone un argumento contra la categoría de análisis de microempresa electoral que merece ser analizado. Según este autor, esta posee muy poca o nula capacidad explicativa. Cabe mencionar el argumento de Sartori (2005) en el sentido de que hay partidos que pueden ser, en sí, una confederación de pequeños movimientos. 
didato obtiene un número importante de votos en comparación con sus compañeros. Además, había un castigo para la dispersión: un umbral que depuraba partidos que no alcanzaran la cifra (Pérez, 2011). El mecanismo del voto preferente, aunque dejaba un camino abierto a los personalismos, solucionaba el problema de la ubicación de un político en una lista cerrada, en la cual quien está de primero saldrá con más ventaja sobre sus copartidarios (Arenas y Bedoya, 2009).

Por supuesto, estos mecanismos disminuyeron el número de partidos reales: de veintiocho en el 2003, se pasó a doce en el 2015, lo que conforma un situación más pragmática y que consolida estructuras partidistas fuertes que no obliga a enfrentar la posibilidad de perder la personería jurídica. De otro lado, con la ley de bancadas se buscaba también mejorar la disciplina partidista en el ámbito legislativo y lograr que los representantes del partido actuaran como un solo cuerpo.

Ante partidos más sólidos se crean nuevos movimientos a costa de los tradicionales y en esta vía Cambio Radical y La U se estructuraron como los más consolidados, ambos con alcance nacional. Un análisis de las trayectorias de los concejales permitiría un resultado más profundo al respecto; sin embargo, cabe mencionar lo siguiente: entre el 2003 y el 2007 el PLC perdió dos concejales, los cuales migraron a La U y al PCR. Varios políticos que labraron su trayectoria en las toldas rojas o azules se consolidaron con estos movimientos. Dilian Francisca Toro, Roy Barreras y Roosevelt Rodríguez por los rojos y Germán Medina Scarpetta, son algunos casos que muestran que la reforma política, al incentivar la cohesión y castigar la fragmentación, incidió en el hecho de que varios políticos con capital electoral se movieran de un partido a otro, por lo general siempre de uno tradicional a uno nuevo.

Aún hay mucho por analizar acerca del sistema de partidos en Cali, principalmente desde una perspectiva comparada para obtener resultados de mayor alcance. Un análisis de las luchas internas de los partidos daría cuenta de los conflictos que las fracciones y facciones han sostenido.

El presente estudio pretendió aportar una mirada sobre los partidos políticos en Cali durante los últimos veinticinco años sobre la base del criterio numérico. Igualmente, al abordar dos momentos institucionales en la historia del país, se consideró el sistema de partidos como una variable dependiente y se sestudiaron los cambios que estos factores institucionales conllevaron. Cali transitó de un bipartidismo atomizado (internamente) a un multipartidismo moderado en el que se consolidaron nuevas fuerzas políticas.

\section{Referencias}

Alcaldía de Santiago de Cali. (2008). Cuentas económicas de Santiago de Cali. Cali: Feriva.

Arenas, J., \& Bedoya, J. (2009). Las lógicas de la competencia electoral en escenarios locales: Medellín, 1988-2007. Estudios Políticos, 39, 39-74.

Arenas, J., \& Bedoya, J. (2015). Incidencia de los cambios en las reglas de la competencia electoral sobre nacionalización del sistema de partidos: las estrategias de los actores políticos en Antioquia, 1997-2011. Colombia Internacional, 85, 81-110. doi: http://dx.doi.org/10.7440/colombiaint85.2015.03

Arenas, J., Bedoya, J., \& Echeverry, L. (2011). Elecciones locales y regionales 2011: Cambios normativos, ajustes partidistas y transformaciones de la élite política. (Apuntes de gobierno \# 5). Medellín: Universidad de Antioquia.

Boudon, L. (1996). Hacia una teoría sobre nuevos partidos políticos. Colombia Internacional, 35, 28-38.

Chomsky, N. (2015). Impacts of free market and US foreign policy on Colombian and Latin American revolution. Rev. Guillermo de Ockham, 13(1), 21-25.

Dávila, A., \& Delgado, N. (2002). La metamorfosis del sistema político colombiano. ¿Clientelismo de mercado o nueva forma de intermediación? En F. Gutiérrez (Ed.), Degradación o cambio: evolución del sistema político colombiano (pp. 319 - 355). Bogotá DC: Grupo editorial norma.

Duque, J. (2011). Políticos y partidos en Colombia. Los liderazgos partidistas en el Frente Nacional prolongado. Bogotá DC: Oveja Negra.

Duque, J. (2014). Partidos y partidismo. Los partidos políticos colombianos y su enraizamiento en la sociedad. Revista de la Facultad de Derecho y Ciencias Politicas, 44(120), 311-347.

Giraldo , F. (2007). Partidos y sistema de partidos en Colombia. En R. Roncagliolo, \& C. Meléndez (Edit.), La politica por dentro: cambios y continuidades en las organizaciones politicas de los paises andinos. (pp. 123-211). Lima: International IDEA.

Gutiérrez, F. (2007). ¿¿Lo que el viento se llevó? Los partidos políticos y la democracia en Colombia. 1958-2002. Bogotá DC: Grupo Editorial Norma.

Hoyos-Gómez, D. (2005). Evolución del sistema de partidos en Colombia 1972-2000. Una mirada local y regional. Análisis político, 55, 45-59.

Kenney, C. (2004). Muerte y renacimiento de un sistema de partidos: Perú 1978-2011. Elecciones, 4, 237-291. 
Llano, H. (2001). Entre transiciones políticas y mutaciones electorales. En F. Giraldo, R. Losada \& P. Muñoz (Edits.), Colombia: elecciones 2000. (pp. 98-120). Bogotá: CEJA.

Mainwaring, S. (2006). Reexaminando la teoría de los partidos políticos en la tercera ola de democratización. En C. Alarcon (Ed.), Metodologías para el análisis político: enfoques, procesos e instituciones. (pp. 309 - 364). México DF: Universidad Autónoma Metropolitana.

Medellín, P. (2005). De la crisis de representación a la representación de la crisis en Colombia. Análisis de las alternativas de salida ofrecidas por el acto legislativo $\mathrm{N}^{\circ} 1$ de 2003 y la ley de bancadas de 2005. En M. Rivera, La reforma política del Estado en Colombia: una salida integral a la crisis. (pp. 20-35). Bogotá DC: Fondo Editorial Cerec.

Molinar, J. (1991). Counting the number of parties: an alternative index. The American Political Science Review, 85(4), 1383-1391.

Montero, J., Gunther, R., \& Linz, J. (Edits.). (2007). Partidos politicos. Viejos conceptos y nuevos retos. Madrid: Trotta.

Ocańa, F., \& Oñate, P. (1999). Índices e indicadores del sistema electoral y del sistema de partidos. Una propuesta informática para su cálculo. Reis: Revista Española de Investigaciones Sociológicas, 86, 223-246.

Pasquino, G. (2011). Nuevo curso de ciencia politica. México DF: Fondo de Cultura Económica.

Pérez, N. (2011). El sistema de partidos colombiano hoy. Partidos y representación en el Congreso después de la reforma de 2003. Ópera, 11, 71-85.

Pinto-Ocampo, M. (2011). Mecanismos en la transformación política en Cali. Fragmentación Partidista, electorado cambiante y responsabilidad política (1988-2007). Estudios políticos, 39, 15-38.

Pizarro, E. (2002). La atomización partidista en Colombia: el fenómeno de las microempresas electorales. En F. Gutiérrez (Ed.), Degradación o cambio: evolución del sistema politico colombiano. (pp. 357 - 401). Bogotá DC: Grupo editorial norma.

Pizarro, E. (2008). Gigantes con pies de barro: los partidos políticos en Colombia. En S. Mainwaring, A. Bejarano \& E. Pizarro (Edits.), La crisis de representación democrática en los paises andinos. (pp. 133-162). Bogotá DC: Grupo editorial norma.
Puyana, J. (2012). Las reformas políticas en Colombia, 20032011: ¿Hacia partidos más responsables? En M. Battle, \& L. Will (Edits.), Politica y territorio. Análisis de las elecciones subnacionales, 2011. (pp. 17-63). Bogotá DC: PNUD.

Puyana, J., \& Battle, M. (2011). El nivel de nacionalización del sistema de partidos colombiano: una mirada a partir de las elecciones legislativas de 2010. Colombia Internacional, 74, 27-57.

Ragin, C. (2007). La construcción de la investigación social. Introducción a los métodos y sus diversidades. Bogotá DC: Siglo del hombre.

Roll, D. (2002). Rojo difuso. Azulpálido. Bogotá DC: Unibiblos.

Roll, D. (2003). Colombia. En M. Alcántara, \& F. Freidenberg (Edits.), Partidos politicos de América Latina. México DF: Fondo de Cultura Económica.

Sartori, G. (2005). Partidos y sistema de partidos. Un marco para el análisis. Madrid: Alianza.

Solano, S. (2005). La utilización del estudio de caso en el análisis local. Región y Sociedad, 17(32), 108 - 144.

Ungar, E., \& Arévalo, C. (2004). Partidos y sistemas de partidos en Colombia hoy: ¿crisis o reordenación institucional? En M. Kornblith, R. Mayorga, S. Pachano, M. Tanaka, E. Ungar, \& C. Arévalo (Eds.), Partidos politicos de la región andina: entre la crisis y el cambio. (pp. 51-71). Lima: International IDEA.

Vanegas, J. (2008). Impacto de la reforma política en los partidos y en el sistema de partidos local. El caso de Cali elecciones 2007. Perspectivas Internacionales, 4(2), 37-72.

Vargas, A. (1994). Los partidos políticos colombianos en la transición: entre el clientelismo y el tecnocratismo. En L. E. Munera (Ed.), Constitución política y reorganización del Estado. (pp. 169-195). Bogotá DC: Universidad Nacional de Colombia,

Venesson, P. (2013). Estudios de caso y seguimiento de procesos: teorías y prácticas. En D. Della Porta, \& M. Keating (Edits.), Enfoques y metodologías en las ciencias sociales. Una perspectiva pluralista (pp. 237-254). Madrid: Akal.

Ware, A. (2004). Partidos politicos y sistemas de partidos. Madrid: Itsmo. 